\title{
Estudo de caso
}

\section{A presença do forame esternal anômalo e a prática de acupuntura no meridiano extra (ren mai) Presence of anomalous sternal foramen and the practice of acupuncture in extra meridien (ren mai)}

Márcio Antônio Babinski, M.Sc.

Professor Assistente de Anatomia do Departamento de Morfologia, Instituto Biomédico, Universidade Federal Fluminense (UFF),

*Instituto Brasileiro de Medicina Tradicional Chinesa (IBMTC), ABA-RJ

\section{Resumo}

O esterno é um osso plano, situada na parede óssea anterior do tórax. Uma vez que, esse osso apresenta vários centros de ossificação, o mesmo pode ser interrompido por um forame anômalo no terço distal. Essa variação tem importância na punção de medula óssea do esterno e principalmente na prática de acupuntura. Portanto o objetivo do presente estudo foi relatar dois casos de variações anatômicas e relacioná-las com a prática de acupuntura, bem como, verificar a descrição das anomalias, precauções e conseqüências na literatura específica de acupuntura.

Palavras-chave: forame esternal, variação anatômica, acupuntura.

\begin{abstract}
Sternum is a plane bone situated in the anterior skeletal wall of the thorax. This bone has some centers of ossification, and can be interrupted by an anomalous foramem in under mid shaft. The importance of this variation is mainly in the punction of sternum medulla and for acupunctural pratice. Therefore, the aim of this study was to relate two cases of anatomical variations and to link them with the acupunctural pratice, as well as to verify the description of the anomalies, precautions and consequences in the acupuncture literature.
\end{abstract}

Key-words: sternal foramen, anatomical variation, acupuncture.

\section{Introdução}

O esterno é um osso plano que forma uma parte da parede óssea do tórax. Consiste de três partes: o manúbrio, o corpo e o processo xifóide, em sentido craniocaudal. Devido a sua acessibilidade e à pequena espessura de sua compacta, o esterno pode ser puncionado por uma agulha, e a medula pode ser aspirada para estudo [1]. Na fase infanto-juvenil apresenta vários centros de ossificação com 3 linhas (cartilagens), mais ou menos distintas que cruzam a face anterior, separando o corpo do esterno em três partes [1,2]. No terço distal, a cartilagem pode ser interrompida por um forame, que é preenchido por cartilagem hialina no vivo [3]. O processo xifóide pode ser além de bífido, ausente e ainda apresentar-se com forame, no qual é mais freqüentemente que o corpo do esterno $[1,3]$.

A teoria da Acupuntura Tradicional Chinesa indica o uso do meridiano (canal) Vaso Concepção (Ren Mai= "nascer" e criar") com grande freqüência para tratamento de problemas dos órgãos genitais internos femininos e.g., dismenorréia, leucorréia, uretrite, ovários policisticos, etc.. No homem, trata impotência, uretrites, hérnias inguinais, cólicas abdominais etc. Uma vez que o meridiano passa pelo tórax trata-se também problemas respiratórios. Este meridiano conecta-se com todos os meridianos Yin, por isso, chama-se "o mar dos meridianos Yin" [4,5]. Percorre da região perianal e na face anterior do tronco passando pelo osso esterno, exatamente na linha média, terminando na depressão do sulco labiomentual inferior [4-8]. Dispõe de 24 acupontos (pontos de acupuntura), sendo que 06 situam-se na região esternal (linha mediana) e destes, 02 sobre áreas de variação xifo-esternal, são eles os pontos Zhongting (vc16) e Shangrong (vc17) [8,9].

$\mathrm{Na}$ literatura até o momento são poucos os trabalhos que descrevem sobre essas variações anatômicas correlacionando, 
sobretudo, as implicações na prática de acupuntura [9] nesses locais. Portanto, o objetivo do presente estudo é relatar dois casos de variações anatômicas no osso esterno e relacionar com a prática de acupuntura bem como, verificar a descrição das anomalias, precauções e conseqüências na literatura específica de acupuntura.

\section{Relato de caso}

Durante as aulas regulares de dissecção e preparo de peças ósseas para as aulas, foi identificado à presença do forame esternal e no mesmo osso a presença do forame no processo xifóide (Fig. 1). Outra peça apresentou a fissura esternal e agenesia de processo xifóide (Fig. 2).

Fig. 1 - Fotomacrografia mostrando o osso esterno masculino com a presença bem definida do forame esternal e outro forame no processo xifóide.

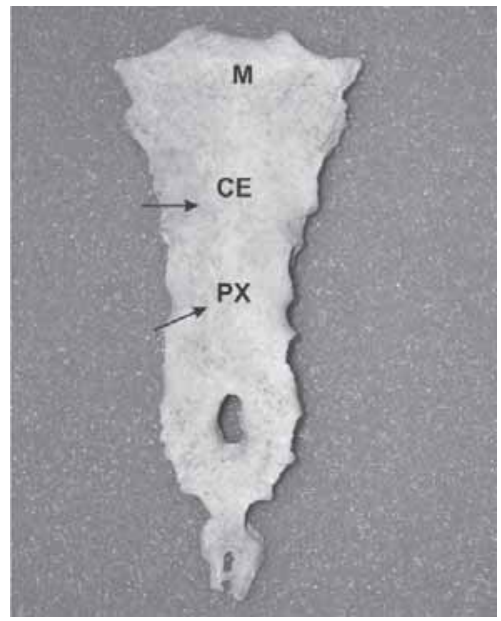

$M=$ Manúbrio, $C E=$ Corpo do Esterno, $P X=$ Processo Xifóide, Seta Superior $=$ Forame Esternal, Seta Inferior $=$ Forame do Processo Xifóide.

Fig. 2 - A fotomacrografia mostra o osso esterno feminino com a presença de uma fissura esternal e a mesma peça ainda é caracterizada pela agenesia do processo xifóide.

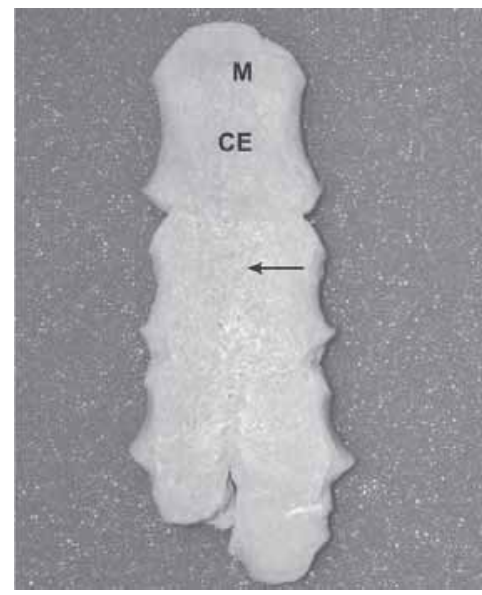

$M=$ Manúbrio, $\mathrm{CE}=$ Corpo do Esterno, Seta = Fissura Esternal.

\section{Discussão}

Derivada dos radicais latinos acus e pungere, que significam agulha e puncionar, respectivamente, a acupuntura visa à terapia e cura das enfermidades pela aplicação de estímulos através da pele, com a inserção de agulhas em pontos específicos chamados acupontos $[4,7,10,11,12]$. Trata-se também de uma terapia reflexa, em que o estímulo de uma área age sobre outra(s). Para este fim, utiliza, principalmente, o estímulo nociceptivo $[12,13]$.

As precauções usuais no exercício da acupuntura no canal Ren Mai (VC), especificamente nos acupontos Zhongting (vc16) e Shangzong (vc17) são relatadas em todos os livros de MTC e Acupuntura, no entanto, existem poucos trabalhos [9] no que se refere as prováveis variações anatômicas. No caso do osso esterno, o acupunturista deve respeitar a angulação da agulha (obliquamente em $45^{\circ}$ ), a profundidade da inserção (geralmente 0,3 á 0,5 Cun = medida chinesa equivalente a 1 polegada) [5,7]. Uma vez atendido esses quesitos e anteriormente a eles, um bom exame palpatório local, evitar-se-á a punção cardíaca que em conseqüência poderia causar o tamponamento cardíaco [7], no caso do forame esternal (Fig. 3). As variações anômalas no forame xifóide poderiam ainda perfurar o fígado (Fig.4) na inspiração.

Fig. 3 - Desenho esquemático de um corte transversal do tórax ao nível da vértebra $T 7$ representando uma possivel perfuração do coração pela presença do forame esternal conforme Fig. 2.

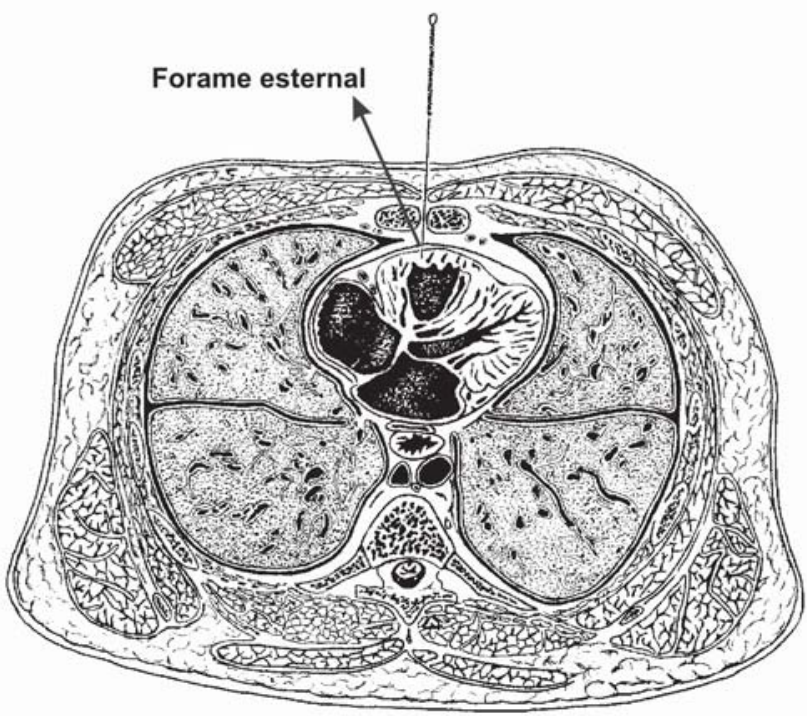

Muitas variações anatômicas originam-se de desvios no desenvolvimento embrionário normal [2,3] e o interessante é que elas acabam por testar os conhecimentos do profissional de saúde ou afligi-lo. No caso do osso esterno as variações de forma estão geralmente relacionadas com o tipo de desenvolvimento. Duas faixas intramembranosas longitudinais unem as extremidades anteriores das costelas em desenvolvimento no início da vida embrionária. Estas 
faixas se fundem e forma uma estrutura mediana única, o esterno $[1,2]$.

Fig. 4 - Desenho esquemático de um corte transversal do tórax ao nivel da vértebra T10 representando uma possivivel perfuração do lobo esquerdo do figado pela presença do forame e ou fissura no processo xifoide.

A fusão completa conduz a uma série de simples centros

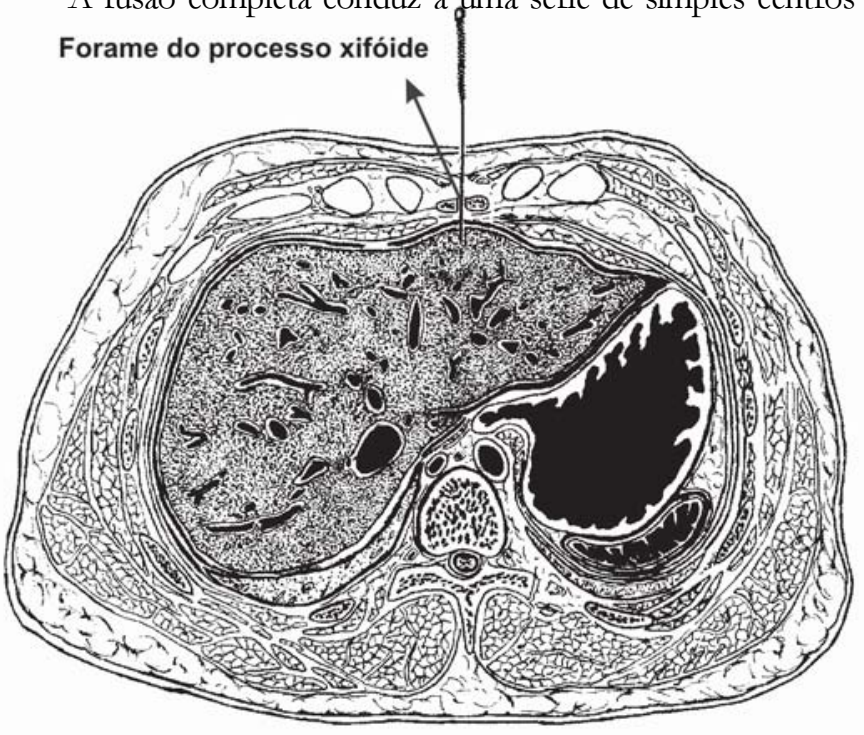

medianos de ossificação, que estão presentes no manúbrio e em cada um dos segmentos corporais na época do nascimento. No entanto, pode não existir centro para o quarto segmento. A fusão incompleta predispõe a ossificação bilateral, especialmente no terceiro e no quarto segmentos. O grau em que existem centros de ossificação bilateral determina a forma do osso adulto. A fusão ainda menos íntima leva à formação de um forame esternal ou a fissura esternal completa [1,9]. A variação descrita nesse trabalho e contida nas figuras (1 e 2), refere-se a esse tipo de anomalia.

O centro de ossificação aparece no processo xifóide durante a infância. Os centros do corpo esternal fundemse entre o fim da puberdade e o início da idade adulta. Ocasionalmente ocorre a interrupção por um forame também no processo xifóide [3], o qual, foi visto nesse trabalho (figura 1). Eles se ossificam durante a puberdade e podem articular-se com o manúbrio ou fundir-se com ele. O esterno pode ser muito fundo ou deprimido ("tórax em funil"), mas tal condição não causa, necessariamente, sintomas $[1,2]$ e também não interfere na prática de acupuntura. $\mathrm{Na}$ literatura até o momento não temos conhecimento de descrição dessas variações anatômicas correlacionando, sobretudo, as implicações na prática de acupuntura nesses locais.

Segundo Chen [7], nos últimos 30 anos, muitos artigos e livros têm sido publicados sobre estruturas anatômicas dos acupontos. Todavia, observamos que a maioria da literatura especializada não aborda as prováveis variações anatômicas que podem surpreender o profissional, outrossim, é ligeiramente abordado sobre as precauções. Dos poucos autores, Chen [7] em sua obra: "Anatomia topográfica dos pontos de acupuntura" sugere aos leitores "não inserir a agulha profundamente, uma vez que pode atravessar a cavidade torácica dentro do pericárdio e do coração, causando sangramento maciço". Com a mesma sugestão o autor indica esse cuidado ainda para os acupontos Yutang (vc18) e Zigong (vc19). No caso do acuponto Huagai (vc20) "não inserir a agulha profundamente, uma vez que pode penetrar através do timo infantil ou cavidade torácica dentro do adulto dentro da traquéia". Sendo assim, essa é uma das poucas obras na literatura que indica a real conseqüência da inserção da agulha sem um maior cuidado, no que tange a inclinação e profundidade da superfície. Outros livros $[4,5,8]$ descrevem somente a localização exata do ponto, bem como, o trabalho de Yamamura et al. [9].

Além do empecilho semântico, a prática da acupuntura se depara com deficiências no ensino e difusão científica $[12,14]$. Muitos dos profissionais (de formação técnica) habilitados a exercer a acupuntura tiveram apenas o direcionamento para o cuidado com a estrutura normal, i.e., "desviar" a artéria, o nervo e a veia, porém lhes falta a orientação das variações anatômicas. Outrossim, cabe lembrar que isso é de responsabilidade dos educadores dos cursos em Acupuntura. Portanto, o objetivo deste trabalho, destinou-se a relatar dois casos de variações anatômicas, com intuito informativo de chamar a atenção para estes fenômenos que alteram a estrutura e que tem implicação na prática de acupuntura.

É contra indicada a instituição do tratamento com acupuntura antes de um elaborado diagnóstico segundo a MTC, pois se corre o risco de mascarar ou alterar os sinais clínicos [15], Portanto, no diagnóstico e tratamento pela acupuntura, corroboramos que é necessário o conhecimento anatômico para exame físico através da Anatomia palpatória de superfície, bem como, a necessidade dos conhecimentos das possíveis variações, para que os profissionais acupunturistas não sejam traídos pelas anomalias do desenvolvimento estrutural humano ou ainda pela ignorância, i.e., falta de bom senso em seguir as indicações de angulação e profundidade das agulhas.

\section{Agradecimentos}

O autor agradece ao acadêmico Rafael Leite Roquette Maciel do curso de Biomedicina da Universidade Federal Fluminense (UFF) pelo prestimoso apoio técnico nos desenhos esquemáticos.

\section{Referências}

1. Gardner E, Gray DJ, O'Hailly R. Anatomia: estudo regional do corpo humano, 4 ed. Rio de Janeiro: Guanabara Koogan; 1988. p.255-6. 
2. Williams P, Warwick R, Dyson M, Bannister LH. Gray: Anatomia, 37 ed. Rio de Janeiro: Guanabara Koogan; 1996.p.303-5.

3. Bergman RA, Thompson SA, Afifi AK, Saadeh FA. Compendium of human anatomic variation: text, atlas, and world literature. $1^{\text {st }}$ ed. Baltimore: Urban \& Schwarzenberg; 1988. p.145-6.

4. Wen TS. Acupuntura clássica chinesa. 2 ed. São Paulo: Cultrix; 1989. p.147.

5. Chonghuo T. Tratado de Medicina Chinesa. 1 ed. São Paulo: Roca; 1993. p.107-11.

6. Mann F. Acupuntura: a arte chinesa de curar. 1 ed. São Paulo: Hemus; 1994. p.74-5.

7. Chen E. Anatomia topográfica dos pontos de acupuntura. 1 ed. São Paulo: Roca; 1997. p.153-61.

8. Cricenti SV. Acupuntura e Moxabustão. 1 ed. São Paulo: Manole; 2001.p.51-4.

9. Yamamura Y, Esper RS, Cricenti SV. Forames esternais e os pontos de acupuntura VC-17 (Shanzhong) e VC-16
(Zhongting) do canal curioso Ren Mai. Rev Paulista Acupunt 1996; 2(1):29-33.

10. Jaggar D. History and basic introduction to veterinary acupuncture. Problems in Veterinary Medicine 1992; $4(1): 13-5$.

11. Schoen AM. Introduction to veterinary acupuncture: scientific basis and clinical aplications. In: Annual convention of the american association of equine practioners. California Proceedings 1993. p.39.

12. Scognamillo-Szabó MVR, Bechara GH. Acupuntura: bases científicas e aplicações. Ciência Rural 2001;31(6):109199.

13. Lundeberg T. Peripheral effects of sensory nerve stimulation (acupuncture) in inflammation and ischemia. Scand J Rehabil Med 1993;29:61-86.

14. Cignolini A. Problems of teaching and diffusion of chinese acupuncture in Europe. J Trad Chin Med 1990:10(1):9-12.

15. Altman, S. Acupuncture as an emergency treatment. California Vet 1979;15(1):6-8. 